\title{
Coexistence of Hyperthyroidism and Pulmonary Hypertension
}

\author{
Mediha Ayhan ${ }^{\mathrm{a}}$, Neslihan Soysal Atile ${ }^{\mathrm{b}, \mathrm{c}}$, Engin Guney ${ }^{\mathrm{a}}$
}

\begin{abstract}
We diagnosed pulmonary hypertension concomitant with hyperthyroidism in two female patients referred to our clinic. In both patients' etiology of hyperthroidism were Graves disease. As a result of management of hyperthroidism with antithyroid medical treatment, decline of pulmonary artery pressures were observed. Association of hyperthroidism with pulmonary hypertension has been notified as case reports in the literature. Current classifications do not give place to hyperthyroidism as a cause of secondary pulmonary hypertension. Primary pulmonary hypertension is however an exclusion diagnosis. We report our cases to point to the need of search for hyperthyroidism before diagnosing primary pulmonary hypertension.
\end{abstract}

Keywords: Hyperthyroidism; Pulmonary hypertension

\section{Introduction}

Pulmonary hypertension $(\mathrm{PH})$ is defined as a sustained elevation of pulmonary arterial pressure to more than $25 \mathrm{mmHg}$ at rest or to more than $30 \mathrm{mmHg}$ with exercise, and left ventricular end-diastolic pressure of less than $15 \mathrm{mmHg}$. PH is classified as primary (idiopathic) or secondary according to

Manuscript accepted for December 2, 2011

${ }^{a}$ Adnan Menderes University Faculty of Medicine, Internal Medicine Department, Endocrinology Division, Aydin, Turkey

${ }^{\mathrm{b}}$ Trakya University Faculty of Medicine, Internal Medicine

Department, Endocrinology Division, Edirne, Turkey

${ }^{\mathrm{c} C o r r e s p o n d i n g ~ a u t h o r: ~ N e s l i h a n ~ S o y s a l ~ A t i l e . ~}$

Email: soysaln@yahoo.com

doi:10.4021/jem61w the etiology. Primary $\mathrm{PH}$ is quite rare with a prevalence of $0.1-0.2 / 100$ 000. Secondary PH has well-known reasons as left ventricule dysfunction, myocardial or valvular diseases, congenital heart diseases, left atrial myxoma, severe obstructive or restrictive lung diseases, sleep apnea syndrome, pulmonary emboli and connective tissue diseases. Hyperthyroidism however is not classified as a secondary pulmonary hypertension reason yet.

\section{Case Report}

\section{Case 1}

A 72 years old female patient admitted with the complaints of palpitation, generalized muscle weakness, trembling and hyperhidrosis. On her medical history, she was diagnosed as Type 2 diabetes mellitus. She has used gliclazide MR 30 $\mathrm{mg} /$ day and acarbose $300 \mathrm{mg}$ total daily dose at admission. In her physical examination, thyroid gland was diffusely large, skin was moist and hot. Hand tremor, tachycardia and arrythmia were observed. Thyroid stimulating hormone (TSH), free thyroxin (sT4) and free triiodothyronine (sT3) levels were measured as $0.007 \mu \mathrm{IU} / \mathrm{mL}(0.27-4.2 \mu \mathrm{IU} / \mathrm{mL})$, $2.38 \mathrm{ng} / \mathrm{dL}(0.93-1.7 \mathrm{ng} / \mathrm{dL})$ and $5.56 \mathrm{pg} / \mathrm{mL}(1.8-4.6 \mathrm{pg} /$ $\mathrm{mL}$ ) respectively. Tc $99 \mathrm{~m}$ pertechnetate thyroid scintigraphy was consistent with Graves disease. Antithyroid peroxidase (A-TPO) and thyrotropin receptor antibody (TRAb) were positive. Atrial fibrillation with high ventricular response was detected on electrocardiography. Chest X-ray showed minimal pleural effusion on the right hemithorax. Transthoracic echocardiography notified severe tricuspid regurgitation and systolic pulmonary artery pressure was measured as $55 \mathrm{mmHg}$. Left ventricule function was normal. Pulmonary angiography with computed tomography detected no findings consistent with pulmonary emboli. Biochemical examination of pleural effusion was transudate. Evaluation about secondary PH reasons was negative. PTU total daily dose of $600 \mathrm{mg}$ was given to the patient. On the 10th day of the treatment, patient's cardiac rhythm was returned to sinus rhythm. On the 15th day TSH, fT4 and fT3 were measured as 0.007 $\mu \mathrm{IU} / \mathrm{mL}, 1.62 \mathrm{ng} / \mathrm{dL}$ and $3.67 \mathrm{pg} / \mathrm{mL}$ respectively and pleural 
effusion disappeared at the same period. Radioactive iodine (131I) treatment were performed for Graves disease. On the second month control, pulmonary artery pressure was measured as $35 \mathrm{mmHg}$ by echocardiography and thyroid hormon levels were normal.

\section{Case 2}

A 45 years old female patient admitted to our clinics with the complaints of weakness, hyperhidrosis and weight loss. She was diagnosed as Type 2 Diabetes Mellitus and was using metformine total daily dose of $1700 \mathrm{mg}$. She has no comorbidity else. In the physical examination, her skin was hot and moist, no other pathological finding was detected except tachycardia and tremor at hands. On her laboratory examination, thyroid function tests were found as TSH: $0.005 \mu \mathrm{IU} /$ $\mathrm{mL}(0.27$ - $4.2 \mu \mathrm{IU} / \mathrm{mL}), \mathrm{sT} 4: 7.77 \mathrm{ng} / \mathrm{dL}(0.93$ - $1.7 \mathrm{ng} / \mathrm{dL})$ and sT3: $27.45 \mathrm{pg} / \mathrm{mL}(1.8$ - $4.6 \mathrm{pg} / \mathrm{mL})$. Antithyroglobulin antibody (A-TG), A-TPO and TRAb were positive. Tc $99 \mathrm{~m}$ pertechnetate thyroid scintigraphy was consistent with Graves disease. On the chest X-ray, right costophrenic sinus was obtuse. Echocardiography revealed 1st degree tricuspit regurgitation and $65 \mathrm{mmHg}$ pulmonary artery pressure. No finding about secondary pulmonary hypertension was detected on the examination. Pulmonary high resolution computed tomography evaluation showed no pathological finding except minimal pleural effusion on the right side. PTU total daily dose of $600 \mathrm{mg}$ was given and a significant regression of the patient's complaints was observed in a week. Pleural effusion was regressed on chest X-ray. On the control echocardiography done after 3 months, pulmonary artery pressure was measured as $35 \mathrm{mmHg}$ and thyroid hormon levels were normal.

\section{Discussion}

In addition to our two cases, several cases of $\mathrm{PH}$ associated with hyperthyroidism have been reported [1-3].

Cardiovascular symptoms are oftenly found in hyperthyroidism. Decrease in systemic vascular resistance and increased cardiac output are seen. Tachycardia, atrial fibrillation, high-output heart failure are most common cardiovascular symptoms of thyrotoxicosis. Stimulation of renal sodium reabsorbtion and erythropoietin secretion are suspected to be responsible for preload and cardiac output increase. Increase of thyroid hormones cause also an increase of catecholamine levels in circulation and thereby leads to an increase in sympathetic tone and a decrease in vagal activity. These are supposed to be the main mechanisms lead to PH.

Direct influence of thyroid hormones on the pulmonary vasculature may be another possible mechanism. The regres- sion of $\mathrm{PH}$ after maintanence of euthyroid state may support this mechanism.

Autoimmune mechanisms may also involve pulmonary hypertension in Graves disease. It has been postulated that autoantibodies may cause pulmonary vascular resistance increase and then $\mathrm{PH}$ by damaging pulmonary vascular endothelial cells. Recent studies have found the proofs of autoimmune thyroid disease in $\mathrm{PH}$ patients. Yanai-Landau and colleagues have examined 40 patients with primary (idiopathic) $\mathrm{PH}$ and have found antithyroglobulin antibodies positive in $30 \%$ of the patients [4]. Chu and colleagues have notify that $49 \%$ of patients with primary $\mathrm{PH}$ received diagnosis of autoimmune thyroid disease after clinical, biochemical and serologic evaluation [5]. Armigliato and colleagues assessed 23 patients diagnosed with hyperthyroidism and detected pulmonary hypertension echocardiographically in 15 (65\% of all) patients [6].

Current data shows thyrotoxicosis should be kept in mind while searching etiology of pulmonary hypertension. Hyperthyroidism can be inexpensively detected by measuring the serum thyroid stimulant hormone and it's a treatable entity, so its cardiac manifestations may be reversible. An association between thyroid disease and $\mathrm{PH}$ has been reported, yet the pathogenetic relationship between these conditions remains unclear. Prospective studies, especially about the role of autoimmunity are needed.

\section{References}

1. Thurnheer R, Jenni R, Russi EW, Greminger P, Speich R. Hyperthyroidism and pulmonary hypertension. J Intern Med. 1997;242(2):185-188.

2. Lozano HF, Sharma CN. Reversible pulmonary hypertension, tricuspid regurgitation and right-sided heart failure associated with hyperthyroidism: case report and review of the literature. Cardiol Rev. 2004;12(6):299305.

3. Ma RC, Cheng AY, So WY, Hui DS, Tong PC, Chow $\mathrm{CC}$. Thyrotoxicosis and pulmonary hypertension. Am J Med. 2005;118(8):927-928.

4. Yanai-Landau H, Amital H, Bar-Dayan Y, Levy Y, Gur $\mathrm{H}$, Lin HC, Alosachie IJ, et al. Autoimmune aspects of primary pulmonary hypertension. Pathobiology. 1995;63(2):71-75.

5. Chu JW, Kao PN, Faul JL, Doyle RL. High prevalence of autoimmune thyroid disease in pulmonary arterial hypertension. Chest. 2002;122(5):1668-1673.

6. Armigliato M, Paolini R, Aggio S, Zamboni S, Galasso MP, Zonzin P, Cella G. Hyperthyroidism as a cause of pulmonary arterial hypertension: a prospective study. Angiology. 2006;57(5):600-606. 